\title{
INCREASING ENTREPRENEURSHIP IN ROMANIA THROUGH EUROPEAN STRUCTURAL FUNDS AND EMIGRATION
}

\author{
Mihaela MATEI ${ }^{a^{*}}$, Mihaela IORDACHE \\ ${ }^{a, b}$ Bucharest University of Economies Studies, Romania
}

DOI: $10.24818 / \mathrm{IMC} / 2020 / 03.09$

\begin{abstract}
In its cohesion policy, the European Commission seeks to use the European Structural Funds to help increase the competitiveness of European Union Member States by supporting entrepreneurial activities, mainly aiming at reducing development gaps at both regional and national level. In this context, encouraging entrepreneurship through the allocation of structural funds is a vector of economic growth and a generator of new employment opportunities. In this paper, we explore the effects of government initiatives that encourage entrepreneurship through the minimis schemes Romania start-up plus and Diaspora Start-up within the Human Capital Operational Program as a catalyst for entrepreneurship and job creation during 2014-2020. Based on empirical data, we analyze whether this support through funding had an impact on entrepreneurial activities in the targeted regions, the relationship between entrepreneurial activities on the one hand and the emigration rate and the economic performance of development regions, on the other. Our hypothesis is that there is a high degree of correlation between the number of newly established companies and the economic performance of the development regions, respectively, the emigration rate. The results of this analysis can contribute to increasing the effectiveness of entrepreneurship support policies, especially if the dependence on appropriate support policies is interrelated.
\end{abstract}

KEYWORDS: cluster analysis, entrepreneurship, migration, public policy, regional development

\section{INTRODUCTION}

The interest in the subject of entrepreneurship has grown considerably in recent times, in response to the proliferation of tools provided by the European Union (EU) to stimulate entrepreneurship. This article addresses the de minimis schemes granted through Romania start-up plus (RSP) and Diaspora Start-up (DS) financed by the Human Capital Operational Program (POCU). It aims to identify the role they play at the regional level in stimulating the business environment and entrepreneurship. The two POCU schemes were selected for this analysis from the multitude of entrepreneurial development programs implemented for two reasons: (i) they have a common goal, namely job creation by supporting entrepreneurial culture (all start-ups must generate at least two jobs) and (ii) they have a similar way of implementation through umbrella beneficiaries who provide entrepreneurship training and business start-up support for selected trainees.

Policymakers are paying more attention to entrepreneurship support policies, and a variety of programs and initiatives have been launched in European Member States to support entrepreneurship. The political interest in encouraging entrepreneurship is reflected in the multitude and diversity of initiatives that support entrepreneurship (OECD, 2015; OECD, 2017). Most of these instruments emerge from the premise that entrepreneurial activities have a positive effect on

\footnotetext{
*Corresponding author. E-mail address: mihaela.matei.16@politice.ro
} 
economic growth. This relationship between entrepreneurship and economic development is complex, but there are enough arguments to support this assumption of a positive relationship between entrepreneurship and economic development. Drucker (1985) emphasizes that entrepreneurship can be seen as an "engine of change, innovation and employment" and Ball (2005) shows that through their small and medium enterprises, entrepreneurs can have a strong influence on the success of any industry.

The literature emphasizes that the development of a new business requires additional external funding to ensure its full potential for development by enabling sustainable growth (Petersen \& Rajan, 1994). Although funding sources are diverse, from own funds to loans from friends or family members (Berger \& Udell, 1995; Fraser et al., 2015), access to finance represents an important obstacle in setting up a new business (Fraser et al., 2015). Access to funds provides development opportunities, as most of the time, without access to external funding, the businesses can be unsustainable (Ang, 1992).

In Romania, the structural funds represent an important source of funding for the new microenterprises and SMEs. This research explores the impact of government initiatives that encourage job creation and support entrepreneurship by providing de minimis schemes through the POCU. We explore, at regional level, the effects of two government initiatives: Romania start-up plus (RSP) and Diaspora Start-up (DS). Given that the Romanian labor market is currently facing a massive migration of active labor, we want to investigate the effects of the two government schemes on entrepreneurship at the regional level.

The main research questions in the empirical part of the paper are:

- How are the entrepreneurial activities developed through the RSP and DS programs financed from POCU distributed in the development regions of Romania?

- What is the relationship between the entrepreneurial activities developed by DS at the regional level and the migration rate related to a region?

Our analysis contributes to current research on the role of governments in the entrepreneurial market by suggesting that government financial support can successfully address the lack of incentives for entrepreneurial activity (Guerini \& Quas, 2016). Besides, our findings could guide policymakers in designing initiatives to support entrepreneurship by developing more focused and selective programs (Cumming et al., 2018).

Section 1 has introduced the subject and the objectives of this analysis. The rest of this paper is organized as follows: Section 2 explores the theoretical framework and develops the two hypotheses mentioned earlier. Section 3 discusses interregional disparities, presents the empirical results of descriptive statistics, explains the data used, the methodological approach applied, discusses the evidence on the relationship between regional entrepreneurship activities and the level of development of the region, and correlation with emigration in the region. The paper concludes with final remarks and recommendations in Section 4.

\section{THEORETICAL FRAMEWORK}

When considering the prospect of starting a new business, an entrepreneur looks primarily to develop a business that responds to professional and personal goals within limits of various conditionalities such as the availability of funding sources (Hatten, 2012). Entrepreneurial firms are usually new businesses without previous activity, which makes it challenging to access loans from financial institutions (Berger et al., 2014; Moro et al., 2015) and their novelty increases uncertainty about their future economic performance (Kreiser et al., 2013). So, these businesses must reorient to alternative sources of financing (Berger \& Udell, 2006; Moro et al., 2015).

The problems faced by new businesses in obtaining external funding suggest a disadvantage that translates into a small number of initiatives. Market failure (Rotger et al., 2012) limits the entrepreneurial potential for innovation and job creation (Acs et al., 2018; Wong et al., 2005). 
To combat these risks, the government intervenes through programs that encourage entrepreneurship by supporting individual entrepreneurial activities (Bertoni et al., 2019; Cumming \& $\mathrm{Li}, 2013)$. Tax benefits and government support as subsidies and grants tend to improve the performance of businesses and to reduce the economic risk that entrepreneurs face at the beginning of their new activity. The financial support mechanism for self-employment, as deminimis aid, creates favorable conditions for increasing the number of new businesses.

The European Commission has acknowledged that conditions for start-ups are not as favorable in the EU as in the USA. Besides, EU citizens are less likely to become entrepreneurs than Americans (Grilo \& Thurik, 2006). Particularly in the case of young Europeans, those with experience of international mobility or migration have a higher propensity to become entrepreneurs (Roman \& Paraschiv, 2019). The Commission has stated that "Entrepreneurship can also contribute to fostering social and economic cohesion for regions whose development is lagging behind" (European Commission, 2003) and in January 2013 adopted the Action Plan for Entrepreneurship 2020 to capitalize on Europe's entrepreneurial potential. The European Council of December 2014 emphasized that entrepreneurship is one of the priorities of the Europe 2020 Strategy for smart, sustainable and inclusive growth.

In this context, in Romania, the National Strategy for Sustainable Development of Romania 2030 addresses the issue of entrepreneurship, and sets as targets, among others, the support of small and medium enterprises' activity, financial support for start-ups, and ensuring increased access to microfunding.

Funding for social cohesion within the EU has grown steadily, making development policies an important policy area in the EU. POCU is funded throughthe European Social Fund (ESF) and is a multi-sectoral operational program that supports individual and integrated project initiatives with direct effects on regional and local development. POCU sets investment priorities, specific objectives and actions undertaken by Romania in the field of human resources, and contributes to reducing disparities in economic and social development between Romania and the other EU Member States. The POCU functions as a means of stimulating economic growth and cohesion and supports the achievement of the objectives set in other development challenges such as competitiveness. From the six priorities, Priority 3 "Jobs for all" aims, among other things, to increase employment by supporting non-agricultural businesses in the urban area, to encourage entrepreneurship and self-employment by supporting the establishment of new non-agricultural enterprises, offering deminimis aid for the selected projects. The de minimisaid schemes support access to employment and self-employment with a focus on start-up businesses. The maximum total amount of the de minimis aid that can be granted may not exceed 40,000 Euros.

\section{METHODOLOGY}

Our analysis is based on data obtained from the Ministry of European Funds (MFE), National Institute of Statistics (INS) and Eurostat. All MFE data are microdata that has been aggregated by authors for the NUTS2 level (Eurostat classification). Due to the specifics of the two financing schemes, the Bucharest-Ilfov Region and the activities in the agricultural sector are excluded from the analysis.

The paper focuses on the following hypotheses derived from previous empirical and theoretical research on the relationship between entrepreneurship, interregional disparities, and government policy to support entrepreneurship. Based on recent work (Cumming et al., 2018) on the effects of government initiatives, we formulate two hypotheses:

- H1: Less developed economic regions are characterized by relatively low levels of entrepreneurial activity, while developed regions have an above-average level of entrepreneurial activity. 
- H2: De minimisschemes to support entrepreneurship through the DS are associated with a higher entrepreneurship rate in regions where the emigration rate is higher than the national level.

To verify this hypotheses, a quantitative analysis of start-ups by development regions was carried out, using specific indicators and the results of de minimis schemes RSP and DS. As statistical methods, we have used Pearson coefficient to test the correlation between variables and cluster analysis to group the regions into classes, SPSS being the statistical software used to run the models.

Correlation coefficients are used in statistics to measure how strong the link between two variables is, the most commonly used being the Pearson coefficient. It shows the linear connection between 2 sets of variables. The formula returns a result between -1 and 1 , which means:

- 1 indicates a positive and strong connection. A correlation coefficient of 1 means that for every positive increase in one variable, there is an all-positive increase in the same proportion and the other variable.

- 1 indicates a negative but strong connection. A correlation coefficient of -1 means that a positive increase of one variable influences the decrease of the other variable with the same proportion.

- A result of zero indicates that there is no connection between the analyzed variables. There is no connection between two variables.

The absolute value of the correlation coefficient shows us the strength of the relationship. The higher the number, the stronger the relationship.

Clustering analysis aims to reduce the number of objects or variables to a small number of information entities that are called classes or clusters. This analysis can be applied both among the variables included in the analysis and among the classification of objects. Clustering analysis was first used by Tyron (1939), the first rigorous studies being presented by Sokal and Sneath (1963). Cluster analysis aims to identify classes, groups or clusters with elements as similar as possible within the same class (minimum variability within classes) and as different from each other as if these elements belong to different classes (maximum variability between classes).

\section{THE RESULTS OBTAINED}

\subsection{Descriptive statistics}

There are eight development regions established in Romania, each region comprising several counties. Significant interregional disparities mark Romania's regions. Regional economic disparities have been frequently analyzed (Smith et al., 2002). There is empirical evidence that most of these interregional disparities are related to human capital, such as per capita income or income difference. The identification of regional disparities in terms of economic performance was achieved by applying the dispersion method on purchasing power standard (PPS) per inhabitant, in the period 2009-2018. Except for the Bucharest-Ilfov region, there is a tendency to maintain variance between regions. The North-East region remains at the lowest level of all regions. Although evolution follows a decreasing trend, regional disparities remain. The annual growth rate for the maximum value is lower than the minimum value, which suggests that there is a tendency to reduce divergences in thee conomic performance at the regional level.

In the period 2009-2018, the average value of GDP / inhabitant at regional level registered a significant increase in all regions, the lowest increase of only $62 \%$ being registered in the SouthMuntenia Region, and the highest in the South-East Region where the increase was 85\% (figure 1). GDP / capita growth rate in 2018 compared to 2009 recorded different values from one region to another, the highest being recorded in the South-East Region (47\%), followed by the West Region (45\%), the lowest growth rate being registered in the South-Muntenia Region (23\%). Compared to 
the average value in the EU-27, there is an increase in the importance of national GDP/capita, given the increase of its share at the national level from 25\% (2009) to 34\% (2018). At the regional level, the differences are obvious, registering in 2018 a variation from 21\% (North-East region) to 35\% (West region).

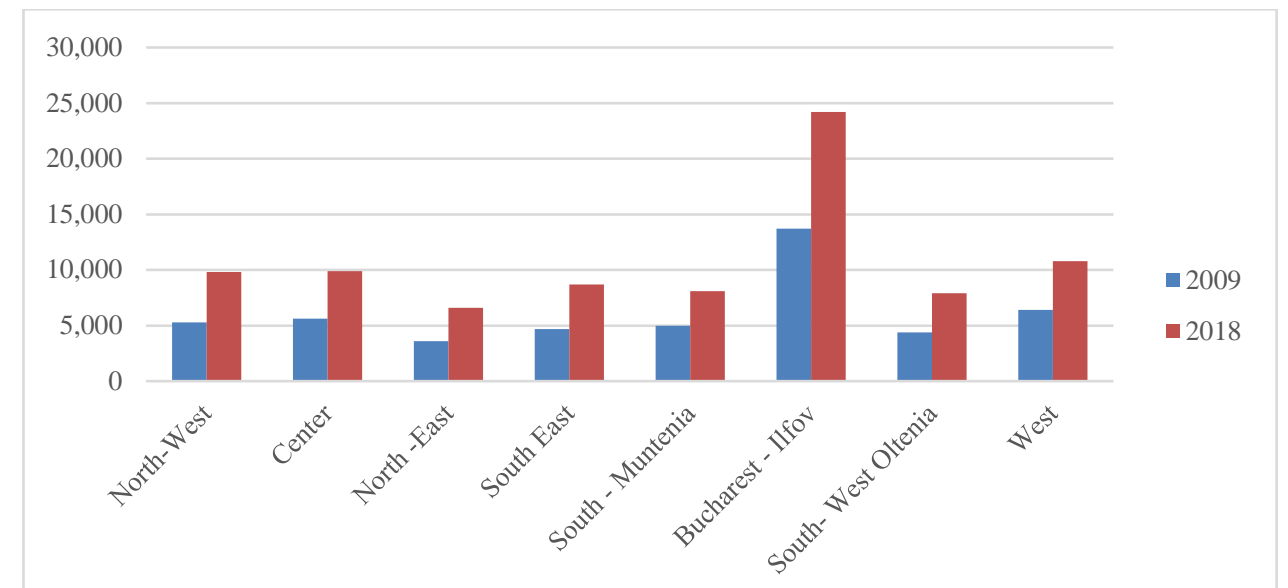

Figure 1.GDP at current market prices by regions - Euro per inhabitant Source:Eurostat, [nama_10r_2gdp]

The analysis of disparities on the labor market was performed using the indicators of employment rate and the rate of risk of poverty or social exclusion (AROPE), in the period 2009-2018, indicators that provide important information on trends in the labor market. Closely correlated with demographic indicators and migration rate, the labor force and the active population followed the same evolution of quantitative decrease. In a different trend, the employment rate of the active population has increased in all regions. The increase of the employment rate of the active population in 2018 compared to 2009 registered different values from one region to another (figure 2), the highest being registered in the Central Region (an increase of 11.6 percent), followed by the South East Region (9.3 percent), the lowest increase rate being registered in the South-Muntenia Region (only 4.9 percent).

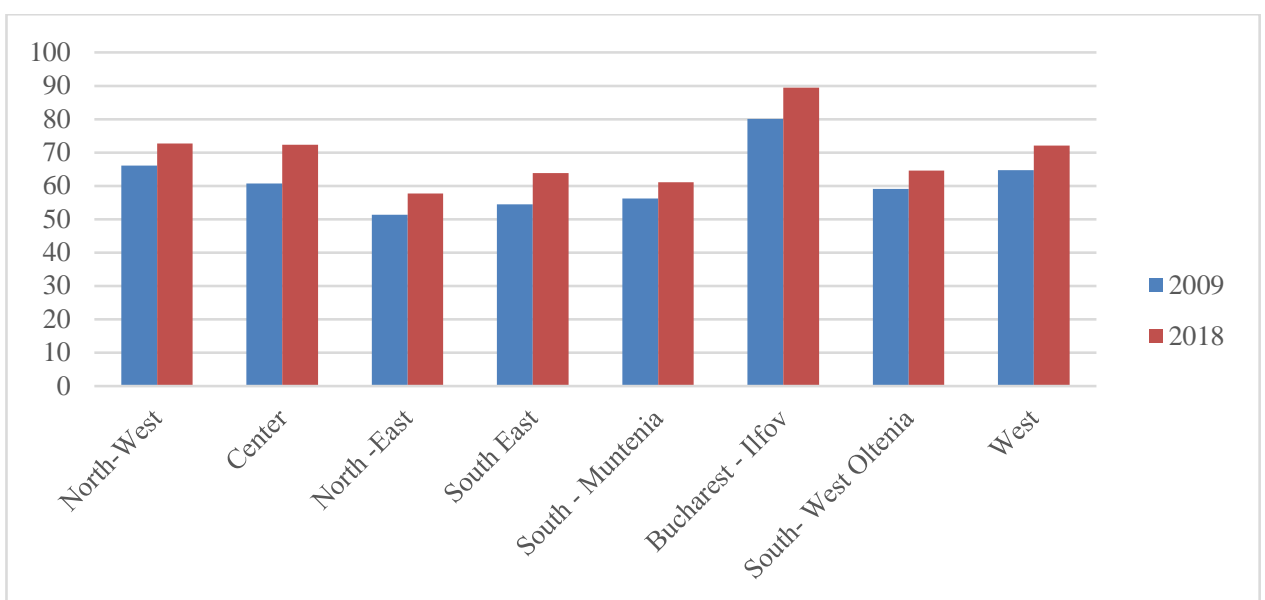

Figure 2. The employment rate of labor resources by development regions Source:Tempo online INS

The regional average rate of risk of poverty or social exclusion decreased between 2009 and 2018 by 10 percentage points. The trend was to decrease in value in most regions. However, significant interregional differences are maintained, the value of the coefficient registered in the North East and 
South West Oltenia regions being double compared to the value registered in the West region (figure 3).

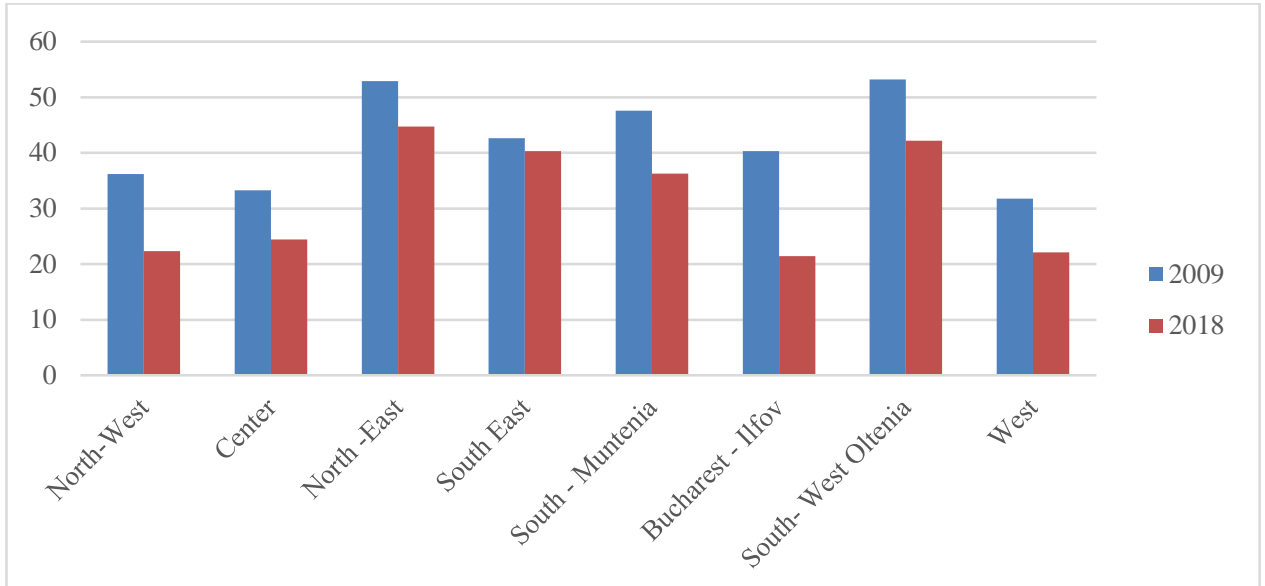

Figure 3. Poverty or social exclusion risk rate (AROPE), by development regions Source:Tempo online INS

In conclusion, from the analysis of regional economic performance and the disparities on the labor market, two major trends can be identified: a relatively slight regional convergence with EU-27, and reduced disparities between the eight NUTS 2 regions in Romania.

The findings regarding the start-ups were based on microdata data on the companies established through RSP and DS. The density of SMEs established through these two de minimis schemes registered at the level of each county varies, revealing the existence of some disparities, more or less accentuated, between different regions. According to MFE data, 8,682 firms were established under the two programs (7,657 under RSP and 1,026 under DS), and those start-ups have created 11,163 new jobs (8,700 under RSP and 2,463 under DS). The regional distribution indicates the Center region with a higher concentration of start-ups $(1,749)$, both in terms of RSP and DS, followed by the regions of South Muntenia, South-West Oltenia and South-East. The region with the lowest share of start-ups was the West (figure 5). The level of entrepreneurial development indicate the Central Region as a new development pole generating economic growth. To be noted that the start-up development in the West region is not in line with the very high level of entrepreneurship of this region. This can be explained by the fact that government programs tend to be more selective than other sources of funding, and government support programs target firms with specific characteristics in terms of factors such as company size and location (Cumming and Li, 2013; Cumming et al., 2018).

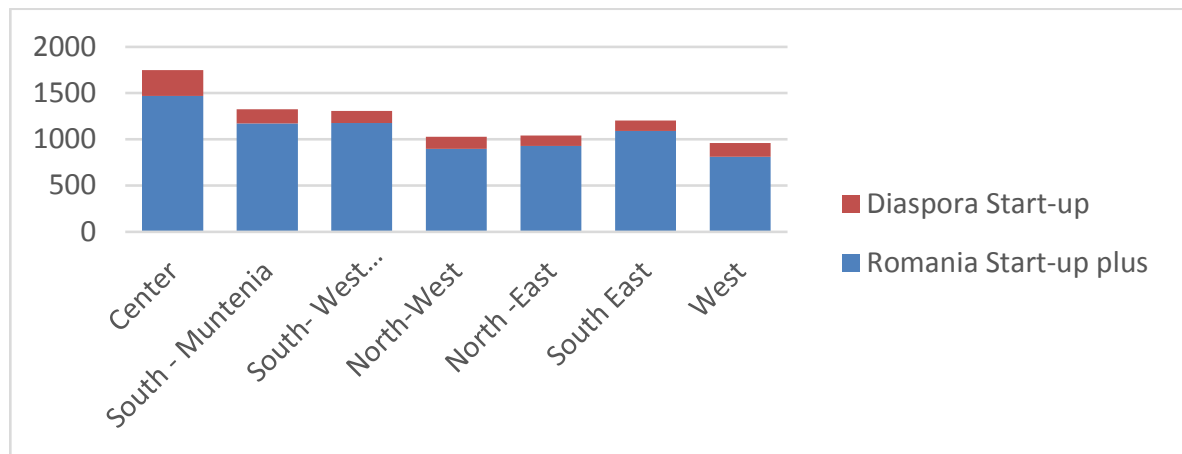

Figure 4. Number of start-ups by de minimis scheme Source: MFE 
The main economic activity of these start-ups is Manufacturing (20\%), the rest of the businesses belonging mainly to the Professional scientific and technical activities, Wholesale and retail trade and Information and communication. According to this structure, it can be concluded that the orientation of companies established through RSP and DS towards technology and innovation is moderate. In the field of manufacturing, the activities are rather a medium-low tech or low-tech. The dominant activities in services are those that involve a low degree of innovation. The fact that most of these businesses were developed in the manufacturing sector supports the consolidation of the tertiary economy, based on high value-added activities. This finding can be explained by the fact that access to government support programs is subject to the evaluation of a business project plan detailing the anticipated effects on policy objectives, such as job creation and sustainability of these jobs. The competitive approach used to allocate government support implies that only those firms that respond to the governmental objectives tend to be successful in the allocation process.

The specificity of de minimis schemes implies that they are designed to address the concreate weaknesses of entrepreneurial firms and associated risks. Consequently, the distribution of start-ups in the economic profile indicates a positive effect on economic diversification at regional level. Thus, we have the following general profile of the start-ups initiated under RSP and DS: 8617 established companies, operating in the manufacturing or professional scientific and technical activities, and having their registered office mainly in Center, South - Muntenia and South-West Oltenia regions.

\subsection{Correlation and cluster analysis}

The variables included in the clustering analysis are Gross Domestic Product, Emigration (including the temporary emigration and definitive emigration), Poverty Rate, Number of Unemployed persons and total number of RSP and DS projects (Table 1). All data used for clustering are taken from INS and are related to 2019.

Table 1. Correlation coefficients

\begin{tabular}{|c|c|c|c|c|c|c|c|}
\hline & $\begin{array}{c}\text { Populatio } \\
\mathbf{n}\end{array}$ & $\begin{array}{c}\text { Number of } \\
\text { unemploy } \\
\text { ed }\end{array}$ & $\begin{array}{c}\text { Net } \\
\text { incomes }\end{array}$ & ISD & GDP & $\begin{array}{c}\text { Poverty } \\
\text { rate }\end{array}$ & $\begin{array}{c}\text { Emigratio } \\
\mathbf{n}\end{array}$ \\
\hline Romania Start-up Plus & -0.01 & 0.22 & -0.32 & 0.33 & 0.12 & 0.12 & -0.05 \\
\hline Diaspora Start-up & -0.19 & -0.38 & 0.36 & 0.77 & 0.31 & -0.49 & -0.25 \\
\hline $\begin{array}{c}\text { Total number of start-ups } \\
\text { RSP and DS }\end{array}$ & -0.05 & 0.10 & -0.18 & 0.44 & 0.17 & -0.01 & -0.10 \\
\hline Number of start-ups RSP & -0.21 & 0.23 & -0.38 & -0.05 & -0.28 & 0.28 & -0.20 \\
\hline
\end{tabular}

Source: Authors' elaboration

The classification method applied to test hypothesis 1 is related to hierarchical cluster analysis. As we have shown above, this type of analysis groups the objects, in this case - the seven implementation regions, based on measuring the distances or similarities between them. We considered the 5 variables presented above. Such method of amalgamation starts from 7 clusters, represented by all regions, which are to be gradually merged, relaxing the grouping criterion until reaching a single cluster containing all the objects. The desired number of clusters is not required as input, the grouping is done naturally, and the user can observe the number of classes that are prefigured. In the first phase, we have calculated the distances between the 7 objects. For example, Table 2 shows the distances between regions. 
Table 2. City-Block distances

\begin{tabular}{|l|ccccccc|}
\hline & $\begin{array}{c}\text { North- } \\
\text { West }\end{array}$ & Center & North-East & South-East & $\begin{array}{c}\text { South } \\
\text { Muntenia }\end{array}$ & $\begin{array}{c}\text { South-West } \\
\text { Oltenia }\end{array}$ & West \\
\hline North- West & 0 & 46038915 & 1124568890 & 517687563 & 269145827 & 2632539406 & 849397498 \\
Center & 46038915 & 0 & 860009307 & 288898390 & 270616236 & 2027560623 & 668587831 \\
North-East & 1124568890 & 860009307 & 0 & 209138421 & 569621089 & 1293265328 & 1834996416 \\
South-East & 517687563 & 2888988390 & 209138421 & 0 & 369743090 & 1091693217 & 954530747 \\
South & 269145827 & 270616236 & 569621089 & 369743090 & 0 & 2724394325 & 1696054607 \\
Muntenia & & & & & & & \\
South-West & 2632539406 & 2027560623 & 1293265328 & 1091693217 & 2724394325 & 0 & 1320756108 \\
Oltenia & & & & & & & \\
West & 849397498 & 668587831 & 1834996416 & 954530747 & 1696054607 & 1320756108 & 0 \\
\hline
\end{tabular}

Source: Authors' elaboration

The distances appear in the form of a symmetric matrix, in which the element $(i, j)$ shows the distance of Manhattan between the region $i$ and $j$ in the 5-dimensional space defined by the 5 variables included in the analysis. The elements that make up the main diagonal are equal to 0; they represent distances between objects for which $i=j$. The matrix is symmetric, i.e.: $d(i, j)=d(j, i)$. We used the Ward method to aggregate the regions. By this method, clusters are formed, so that for each step, assigning an object to a cluster minimizes the variance within the cluster (Figure 7).

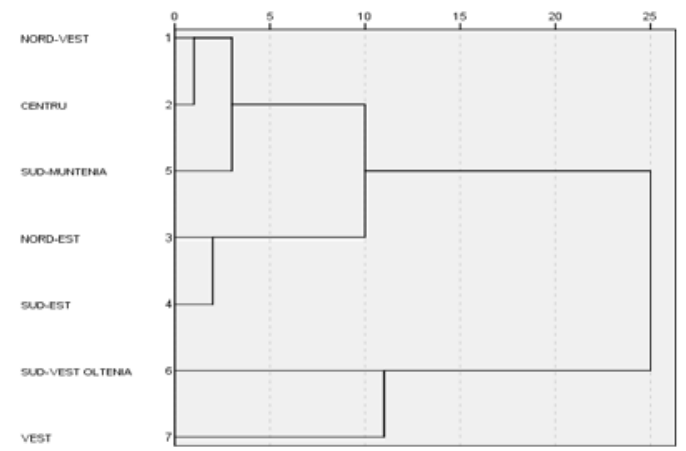

Figure 7. Amalgamation dendrogram for Ward's method

Source: Authors' elaboration

This graph visually suggests where the clustering process should naturally be interrupted; moving to the right, the distance between objects increases (the length of the right segments increase), bigger clusters are formed, and the intra-cluster variance is larger. In the first phase, a slow evolution is observed, the increase of the distance being small. Significant increases in distances follow, the last 2 steps being the joining of objects that have very large distances. Because the amalgamation distance from step $\mathrm{i}$ is greater than the amalgamation distance from step i-1 (whatever i), we can say about the chosen method that it meets the condition of monotonicity and is ultra metric. The distance can be an optimal criterion in determining the number of clusters to be retained. We suggest the retention of 4 clusters as marked in figure 7 . Thus the first cluster consists of the NorthWest, Center and South-Muntenia regions. The second cluster is composed of the North-East and South-East Region, and the South-West Oltenia and West remain alone in the cluster. 


\subsection{Discussion}

In this section, we discuss how funding affects specific indicators. The aim is to analyze the dynamics of enterprises established with the support of RSP and DS, as well as the link with key indicators such as the number of unemployed persons, FDI, GDP per capita, and relative at-risk-ofpoverty rate by NUTS region. We also aim to identify the extent to which the number of companies established by DS in regional profile correlates with net migration rate.

The analysis of the data regarding the distribution by regions of the average number of unemployed highlights a series of characteristics common to those encountered in the case of distribution of the start-ups at the regional level, marked by major discrepancies between different geographical areas of Romania. Most NUTS2 regions with above-average start-up rates have below-average unemployment rates. The number of unemployed persons is related to both the total number of start-ups and the amount financed, but the connection is weak.

Foreign direct investment is in a direct and strong link with the number of DS projects. This can be explained by the fact that Romanians abroad chose to invest in regions where foreign investors have already had a contribution to capital, technology, know-how, or international competitiveness. The same conclusion is supported by the poverty rate which is inversely proportional to the number of projects in DS, the connection being of medium intensity, and directly proportional and weak to the amount financed within the RSP project.

Our analysis highlights interregional disparities between regions in terms of GDP/capita, although these disparities have decreased slightly in recent years. As in the case of the other indicators, there are interregional territorial disparities. There is a direct correlation, of different intensities, between GDP per capita and the number of start-ups, but there are development regions where this rule is not valid. GDP is inversely proportional to the financed amount, the intensity being low. One possible explanation may be the greater relevance of necessity entrepreneurship (Bosma, 2009; Wong et al., 2005).

Regardless of the program or quantification, the connection with the population is negative and very weak. However, the emigration (including both temporary and definitive emigration) is inversely proportional whether we are talking about the number of projects or the amount financed; but the connection is very weak.

\section{CONCLUSIONS}

As shown above, the use of structural funds is an important source of funding for entrepreneurship and job creation in Romania. The selected field is complex and consider the impact of de minimis schemes from structural funds on entrepreneurial activity in development regions and in regions where the emigration rate is higher than the national average. Our results suggest that government initiatives regarding support programs have a positive effect on development of start-ups.

Analyzing the correlation coefficients between the main variables and the RSP and DS programs, we can conclude that neither the first hypothesis, according to which backward economic regions are characterized by relatively low levels of entrepreneurial activities, neither the second hypothesis, according to which the policies for supporting entrepreneurship through the DS scheme are associated with their higher entrepreneurship rates in the regions where the emigration rate is higher, are not supported in the case of projects financed by RSP and DS.

The limitations of our activity suggest other areas of investigation. Firstly, the authors believe that the full effects of RSP and DS will completely manifest after a longer period, so the analysis carried out must be continued. Subsequent investigations will complete the analysis of the impact that de minimis schemes have on the development of entrepreneurship, as well as the sustainability of these initiatives. Secondly, the current analysis can be detailed at the level of economic sectors correlated to the development of the labor market in Romania and government initiatives that support the economics sectors' development. 


\section{REFERENCES}

Acs, Z. J., Estrin, S., Mickiewicz, T. \& Szerb, L., (2018). Entrepreneurship, institutional economics, and economic growth: an ecosystem perspective. Small Business Economics, 51, 501-514.

Ang, J. S. (1992). On the theory of finance for privately held firms. The Journal of Entrepreneurial Finance, 1(3), 185-203.

Ball, S. (2005). The importance of Entrepreneurship to Hospitality, Leisure, Sport and Tourism. Hospitality, Leisure, Sport and Tourism Network.

Berger, A. N. \& Udell, G. F. (1995). Relationship lending and the lines of credit in small firm finance. The Journal of Business, 68(3), 351-381.

Berger, A. N. \& Udell, G. F. (2006). A more complete conceptual framework for SME finance. Journal of Banking \& Finance, 30(11), 2945-2966.

Berger, A. N., Goulding, W. \& Rice, T. (2014). Do small businesses still prefer community banks?. Journal of Banking \& Finance, 44, 264-278.

Bertoni, F., Martí, J. \& Reverte, C. (2019). The impact of government-supported participative loans on the growth of entrepreneurial ventures. Research Policy. 48(1), 371-384.

Cumming, D. \& Li, D. (2013). Public policy, entrepreneurship and venture capital in the United States. Journal of Corporate Finance, 23, 345-367.

Cumming, D. J. \& Vismara, S. (2018). New players in entrepreneurial finance and why they are there. Small Business Economics, 50, 239-250.

Drucker, P. F. (1985). Innovation \& Entrepreneurship: Principles and Practices. New York, NY: HarperTrade.

European Commission. (2003). Green Paper. Entrepreneurship in Europe. Brussels.

Fraser, S., Bhaumik, S.K. \& Wright, M. (2015). What do we know about entrepreneurial finance and its relationship with growth?. International Small Business Journal: Researching Entrepreneurship, 33, 70-88.

Grilo, I. \& Thurik, R. (2005). Latent and Actual Entrepreneurship in Europe and the US: Some Recent Developments. The International Entrepreneurship and Management Journal, 1, 441459.

Guerini, M. \& Quas, A. (2016). Governmental venture capital in Europe: screening and certification. Journal of Business Venturing, 31(2), 175-195.

Hatten, T. (2012). Principles of Small Business Management, 5th edition. China: South-Western Cenage Learning.

Kreiser, P. M., Marino, L. D., Kuratko, D. F. \& Weaver, K. M. (2013). Disaggregating entrepreneurial orientation: the non-linear impact of innovativeness, proactiveness and risktaking on SME performance. Small Business Economics, 40, 273-291.

Moro, A., Maresch, D. \& Fink, M. (2015). Reduction in information asymmetry and credit access for small and medium-sized enterprises. Journal of Financial Research, 38(1), 121-143.

OECD. (2015). New Approaches to SME and Entrepreneurship Financing: Broadening the Range of Instruments. Paris.

OECD. (2017). Evaluating Publicly Supported Credit Guarantee Programmes for SMEs. Paris.

Petersen, M. A. \& Rajan, R. G. (1994). The benefits of lending relationships: evidence from small business data. The Journal of Finance, 49, 3-37.

Roman, M. \& Paraschiv, D. M. (2019). The Young Entrepreneurs of Europe and the Role of International Mobility. Amfiteatru Economic, 21(13), 763-777.

Rotger, P. G., Gørtz, M. \& Storey, D. J. (2012). Assessing the effectiveness of guided preparation for new venture creation and performance: theory and practice. Journal of Business Venturing, 27(4), 506-521. 
Smith, A., Rainnie, Al., Dunford, M., Hardy, J., Hudson, R. \& Sadler, D. (2002). Networks of Value, Commodities and Regions: Reworking Divisions of Labour in Macro-Regional Economies. Progress in Human Geography, 26(1), 41-63.

Sokal, R. \& Sneath, P. (1963). Principles of numerical taxonomy. San Francisco, USA: W.H. Freeman Co.

Tyron, R. (1939). Cluster Analysis. Ann Arbor, USA: Edwards Brothers.

Wong, P. K., Ho, Y. P. \& Autio, E. (2005). Entrepreneurship, innovation and economic growth: evidence from GEM data. Small Business Economics, 24, 335-350. 